\title{
Geographic and temporal patterns in the acoustic detection of sperm whales Physeter macrocephalus in the central and western North Pacific Ocean
}

\author{
Karlina P. Merkens ${ }^{1, *}{ }$, Anne E. Simonis ${ }^{1}$, Erin M. Oleson ${ }^{2}$ \\ ${ }^{1}$ NOAA Affiliate through Lynker Technologies - Contractor to Pacific Islands Fisheries Science Center, Honolulu, HI 96818, USA \\ ${ }^{2}$ NOAA NMFS Pacific Islands Fisheries Science Center, Honolulu, HI 96818, USA
}

\begin{abstract}
The easily identifiable, high-amplitude echolocation signals produced by sperm whales Physeter macrocephalus make the species ideal for long-term passive acoustic monitoring. Sperm whale signals were manually identified in the recordings from high-frequency acoustic recording packages monitoring 13 deep-water locations across the central and western North Pacific Ocean from 2005 to 2013, constituting the longest passive acoustic study of sperm whales to date. The species was detected at all of the sites, with the highest detection rate at Ladd Seamount ( $>18 \%$ of analyzed periods) and the lowest rates at equatorial sites $(<1 \%$ of analyzed periods). Generalized additive models and generalized estimating equations were used to produce explanatory models to assess temporal and geographic patterns. The model variables included diel phase, lunar day, day of the year, year, and site. The site-specific variability in detection rates was high across the North Pacific, but there were also common patterns, including a seasonal trend, with decreased detections during the summer or fall, and a diel trend, with increased detections at night. There appeared to be a seasonal movement pattern, with minimum detection rates occurring later in the year at more northerly sites. The nocturnal pattern was seen across all data sets but was not strong at equatorial locations. Although lunar cycles were important at many sites, there was no consistent trend at any spatial scale. Overall, this analysis confirms the broad distribution of sperm whales across the North Pacific and highlights the subtle temporal patterns in their acoustic activity, which may be related to shifts in animal behavior or movement.
\end{abstract}

KEY WORDS: Sperm whale $\cdot$ Physeter macrocephalus $\cdot$ Passive acoustic monitoring $\cdot$ Generalized estimating equations $\cdot$ Generalized additive models $\cdot$ GEE $\cdot$ GAM

\section{INTRODUCTION}

Sperm whales Physeter macrocephalus are the largest odontocetes, and individuals of this cosmopolitan species can be found in all the world's oceans between the equator and the polar ice edges. Despite their global presence and a long history of being hunted by humans, the current distribution of sperm whales remains unknown in many regions because of their deep-diving behavior and preference for offshore, deep-water habitat (Baumgartner et al. 2001, Becker et al. 2010). Additionally, because of the chal-

${ }^{*}$ Corresponding author: karlina.merkens@noaa.gov lenges in observing them, little is known about their activity patterns over the course of hours, days, and seasons, particularly for animals living in the vast central and western North Pacific Ocean. Sperm whales have been listed as endangered throughout their range under the US Endangered Species Act since 1970 and are considered Vulnerable by the International Union for the Conservation of Nature Red List (Taylor et al. 2008).

Past North Pacific sperm whale distribution has been inferred from analyses of historical whaling records (Kasuya \& Miyashita 1988, Smith et al. 2012, 
Mizroch \& Rice 2013, reviewed by Jaquet 1996). In this region, sperm whales have been sighted or hunted at all latitudes, although catches were concentrated along equatorial, subtropical, and subarctic frontal zones during 19th century Yankee whaling (1761-1924), while during modern 20th century whaling (1925-present), catches were made primarily in productive coastal areas such as the Aleutian archipelago and coasts of North America and Japan (Jaquet 1996, Smith et al. 2012, Mizroch \& Rice 2013, Ivashchenko et al. 2014). Given these records from the past, we would expect to find higher concentrations of sperm whales along frontal zones and at the equator, following Mizroch \& Rice (2013, their Fig. 1).

Modern efforts to assess distribution have been limited to smaller regions within the basin (e.g. Barlow \& Taylor 2005, Fulling et al. 2011, Forney et al. 2012, 2015, Bradford et al. 2017). These studies used methods such as visual and passive acoustic linetransect surveys, and they highlight an offshore distribution, with sperm whales being detected most frequently in deep water near the continental slope and in the vicinity of oceanic islands. This information, combined with the data from the Yankee whaling era, provides a rough picture of sperm whale distribution in the North Pacific.

While there is some understanding of sperm whale distribution in the North Pacific, there are significant gaps in what is known about their basic biological cycles over varying time scales. For example, despite a large number of studies investigating sperm whale diel behavior, there is no clear consensus. Sperm whales at some times in some locations have clear diel patterns in activity or acoustic behavior, but at other times and/or other locations there is an opposite pattern or no pattern at all, even within the Pacific basin (e.g. Papastavrou et al. 1989, Amano \& Yoshioka 2003, Aoki et al. 2007, Irvine et al. 2017). Activity over longer time scales is even less well understood, with month-long lunar cycles having never been investigated for the species and most analyses of seasonal trends being limited by the duration or seasonal coverage of the data set, once again producing conflicting site-specific results (e.g. Oshumi 1966, Kasuya \& Miyashita 1988, Whitehead 2003, Mellinger et al. 2004, Smith et al. 2012, Giorli et al. 2016).

Data from large networks of autonomous passive acoustic monitoring (PAM) sensors may provide greater insight into the temporal and/or spatial patterns in species such as sperm whales than currently provided by traditional visual survey or tagging methods (Zimmer 2011). Sperm whales are ideal candidates for PAM because they generate high- amplitude signals for navigation, echolocation, and communication (Goold \& Jones 1995, Goold 1999, Madsen et al. 2002, Møhl et al. 2003). The sperm whale acoustic repertoire comprises a variety of signals that are easily identifiable to the species level and are predominantly collections of clicks arranged into distinctive patterns that serve unique functions (Worthington \& Schevill 1957, Watkins \& Schevill 1977, Gordon 1987, Weilgart \& Whitehead 1988, Goold 1999, Møhl et al. 2000, 2003, Madsen et al. 2002). Echolocation clicks were selected for this study because they are generated by sperm whales for navigation and foraging, behaviors which comprise 75 to $80 \%$ of their daily activity budget year-round in tropical and temperate latitudes (Whitehead \& Weilgart 1990, 1991, Whitehead 2003). These clicks are typically high amplitude, with apparent source levels up to $236 \mathrm{~dB}$ re $1 \mu \mathrm{Pa}$ RMS (Møhl et al. 2000, 2003), and broadband, with a $-10 \mathrm{~dB}$ bandwidth ranging between 10 and $15 \mathrm{kHz}$. The center frequency is around 10 to $15 \mathrm{kHz}$ (Madsen et al. 2002, Thode et al. 2002), and the average inter-click interval is 0.5 to $1 \mathrm{~s}$ (Goold \& Jones 1995, Madsen et al. 2002). Previous research has shown that sperm whale echolocation clicks can be detected at distances of 5 to $15 \mathrm{~km}$ or more, depending on the click characteristics and the propagation conditions at a given location (e.g. Madsen et al. 2002, Barlow \& Taylor 2005).

In this study, we identified echolocation clicks in the longest passive acoustic investigation of sperm whales to date, spanning more than 8 yr from 13 locations in the central and western North Pacific Ocean. The instruments were located in places where we expected to detect sperm whales or other deep-diving cetaceans based on historic and modern understanding of the species' distribution. The importance of the location and timing of our detections, as revealed through statistical models, helps define the spatial and temporal presence of sperm whales across the region and allows inference about sperm whale activity patterns and relative abundance across the broader tropical and subtropical North Pacific.

\section{MATERIALS AND METHODS}

\subsection{Acoustic data collection}

The Pacific Islands Passive Acoustic Network is maintained by the NOAA Pacific Islands Fisheries Science Center and consists of 13 monitoring sites at 11 islands and seamounts located across the central and western North Pacific Ocean (Figs. 1 \& 2, 


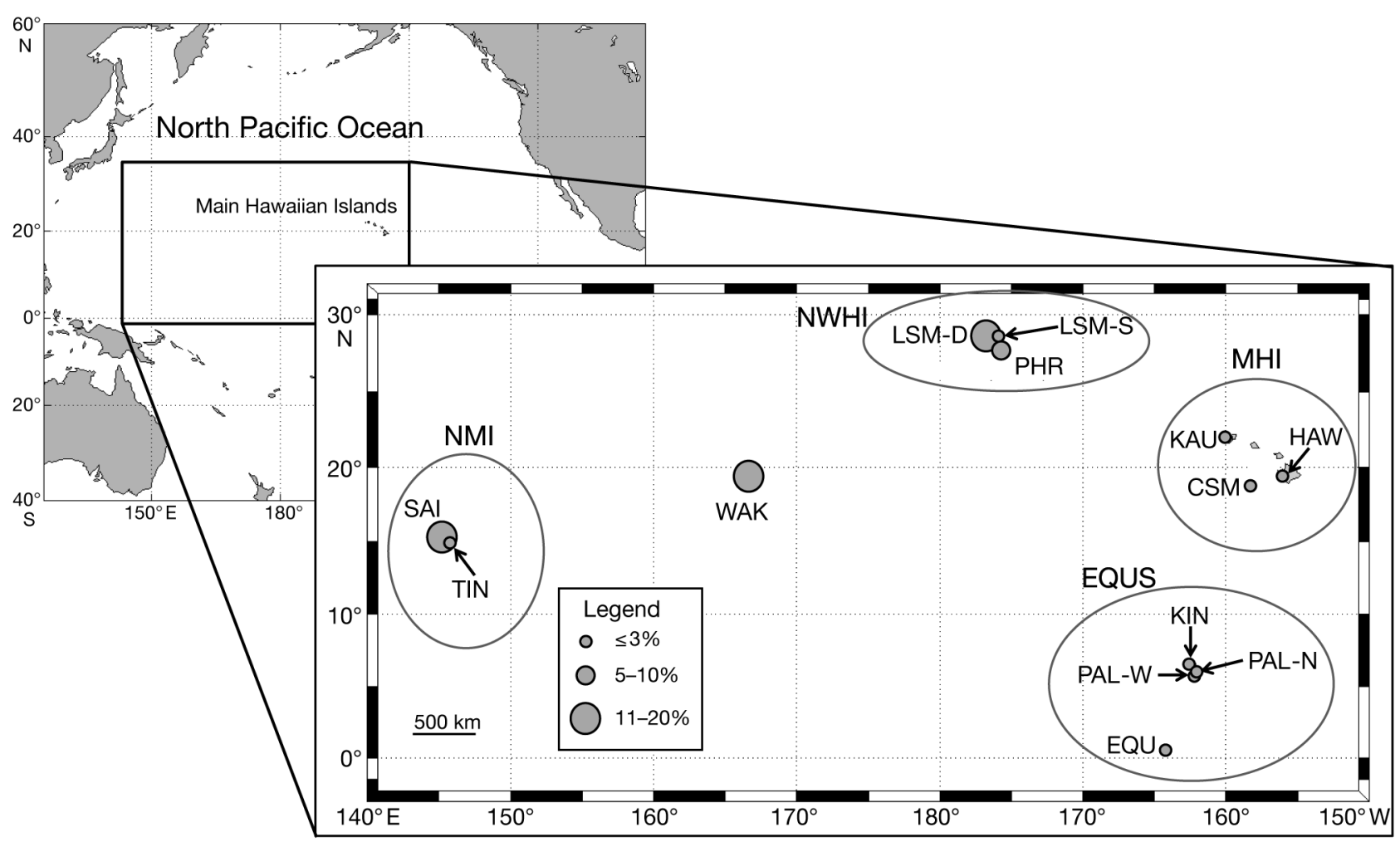

Fig. 1. Monitoring locations across the central and western North Pacific Ocean. Monitoring sites are indicated by gray filled circles. Size of circle indicates relative rate of sperm whale detection at each site. Sites are: Cross Seamount (CSM), Equator (EQU), Hawai'i Island (HAW), Kauai (KAU), Kingman Reef (KIN), Ladd Seamount-Deep (LSM-D), Ladd Seamount-Shallow (LSM-S), Palmyra Atoll-North (PAL-N), Palmyra Atoll-West (PAL-W), Pearl and Hermes Reef (PHR), Saipan (SAI), Tinian (TIN), and Wake Atoll (WAK). Subregions (gray ovals, bold font) are: Main Hawaiian Islands (MHI), Northern Mariana Islands (NMI), Northwestern Hawaiian Islands (NWHI), and Equatorial subregion (EQUS)

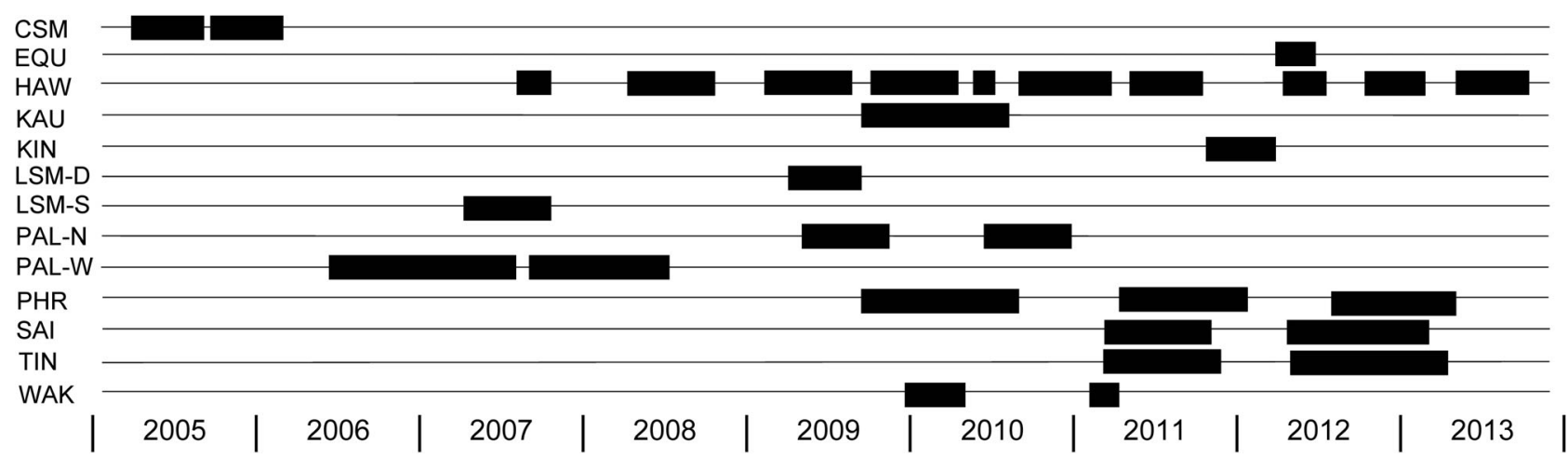

Fig. 2. Recording effort at all sites over time. Black boxes indicate periods of recordings. Site abbreviations as in Fig. 1

Table 1). Each site was selected for monitoring a variety of species (particularly deep-diving cetaceans) based on local bathymetry and the ability to service sites at regular intervals and because each site was known or suspected cetacean habitat. Typical deployment depths for this study (>550 m) were suitable for monitoring deep-diving cetaceans, which commonly dive to depths below $200 \mathrm{~m}$ and echolocate during the deepest parts of their dives (Wat- wood et al. 2006, Davis et al. 2007, Irvine et al. 2017). At each location, a high-frequency acoustic recording package (HARP; Wiggins \& Hildebrand 2007) was deployed, recording at a $200 \mathrm{kHz}$ sampling rate with 16 bit quantization. All HARPs used an omnidirectional ITC-1042 transducer (International Transducer Corporation) suspended at 10 to $30 \mathrm{~m}$ above the seafloor. The frequency response of the hydrophone was flat $( \pm 2 \mathrm{~dB})$ with sensitivity $-200 \mathrm{~dB}$ re $\mathrm{V}$ 
Table 1. Monitoring site details. Recording dates span gaps between deployments, illustrated in Fig. 2; recording was not continuous from start to end dates. Subregions are the Main Hawaiian Islands (MHI), Northwestern Hawaiian Islands (NWHI), Equatorial (EQUS), and Northern Mariana Islands (NMI). Subregion for Wake Atoll is not applicable (NA) because this site is remote from all other sites

\begin{tabular}{|c|c|c|c|c|c|c|c|}
\hline Site & Subregion & Latitude & Longitude & $\begin{array}{l}\text { Depth } \\
\text { (m) }\end{array}$ & $\begin{array}{l}\text { Recording duration } \\
\quad \text { (cumulative d) }\end{array}$ & $\begin{array}{l}\text { Recording dates } \\
\text { (mm/yyyy) }\end{array}$ & $\begin{array}{c}5 \text { min samples } \\
\text { with detections (\%) }\end{array}$ \\
\hline Cross Seamount & MHI & $18^{\circ} 43^{\prime} \mathrm{N}$ & $158^{\circ} 15^{\prime} \mathrm{W}$ & 397 & 359 & 04/2005-05/2006 & 1.7 \\
\hline Equator & EQUS & $00^{\circ} 26^{\prime} \mathrm{N}$ & $164^{\circ} 08^{\prime} \mathrm{W}$ & 1266 & 103 & 03/2012-06/2012 & 0.7 \\
\hline Hawai'i Island & MHI & $19^{\circ} 34^{\prime} \mathrm{N}$ & $156^{\circ} 00^{\prime} \mathrm{W}$ & 630 & 1224 & 08/2007-10/2013 & 1.3 \\
\hline Kauai & MHI & $21^{\circ} 57^{\prime} \mathrm{N}$ & $159^{\circ} 53^{\prime} \mathrm{W}$ & 713 & 296 & $10 / 2009-08 / 2010$ & 2.9 \\
\hline Kingman Reef & EQUS & $6^{\circ} 21^{\prime} \mathrm{N}$ & $162^{\circ} 17^{\prime} \mathrm{W}$ & 859 & 122 & $11 / 2011-03 / 2012$ & 0.7 \\
\hline Ladd Seamount-Deep & NWHI & $28^{\circ} 37^{\prime} \mathrm{N}$ & $176^{\circ} 43^{\prime} \mathrm{W}$ & 1092 & 90 & 05/2009-08/2009 & 18.1 \\
\hline Ladd Seamount-Shallow & NWHI & $28^{\circ} 36^{\prime} \mathrm{N}$ & $176^{\circ} 42^{\prime} \mathrm{W}$ & 117 & 157 & 04/2007-10/2007 & 1.6 \\
\hline Palmyra Atoll-North & EQUS & $5^{\circ} 53^{\prime} \mathrm{N}$ & $162^{\circ} 01^{\prime} \mathrm{W}$ & 800 & 339 & $06 / 2009-12 / 2010$ & 0.7 \\
\hline Palmyra Atoll-West & EQUS & $5^{\circ} 51^{\prime} \mathrm{N}$ & $162^{\circ} 09^{\prime} \mathrm{W}$ & 567 & 742 & $10 / 2006-04 / 2009$ & 0.3 \\
\hline Pearl and Hermes Reef & NWHI & $27^{\circ} 43^{\prime} \mathrm{N}$ & $175^{\circ} 38^{\prime} \mathrm{W}$ & 709 & 878 & $10 / 2009-05 / 2013$ & 9.1 \\
\hline Saipan & NMI & $15^{\circ} 19^{\prime} \mathrm{N}$ & $145^{\circ} 27^{\prime} \mathrm{E}$ & 648 & 437 & $04 / 2011-03 / 2013$ & 11.7 \\
\hline Tinian & NMI & $15^{\circ} 02^{\prime} \mathrm{N}$ & $145^{\circ} 45^{\prime} \mathrm{E}$ & 997 & 548 & $04 / 2011-05 / 2013$ & 1.1 \\
\hline Wake Atoll & NA & $19^{\circ} 21^{\prime} \mathrm{N}$ & $166^{\circ} 41^{\prime} \mathrm{E}$ & 843 & 156 & $01 / 2010-05 / 2011$ & 14.7 \\
\hline
\end{tabular}

$\mu \mathrm{Pa}^{-1}$ from $10 \mathrm{~Hz}$ to $100 \mathrm{kHz}$. Custom-built preamplifiers designed to whiten ambient noise and bandpass filters to reduce high-frequency aliasing were included and were compensated for during analysis.

The data were collected between April 2005 and May 2013 (Fig. 2), although no site was active for the entire duration, resulting in nearly 15 cumulative years of recordings ( 119 TB). The shortest monitoring effort was at the Equator site (122 d), and the longest was at Hawai'i Island (>7 yr). Gaps in data collection sometimes occurred at each site between the end of one instrument deployment and the start of the next, potentially complicating assessment of longer-term temporal patterns from sites with more than 1 deployment. These data gaps ranged from a few hours to many months depending on the battery life, data storage capacity, and HARP servicing schedule.

Passive acoustic data were processed and analyzed using manual click detection methods. Trained analysts (K.P.M., A.E.S.) identified and marked sperm whale echolocation clicks visualized in long-term spectrograms. Analysts viewed $1 \mathrm{~h}$ windows of longterm spectral averages (LTSA; Wiggins \& Hildebrand 2007) (5 s time average, $100 \mathrm{~Hz}$ frequency bins), and 10 s spectrograms were used to confirm species identification (Fast Fourier transform length 2000 points, $75 \%$ overlap, bandwidth $0-40 \mathrm{kHz}$ ). An encounter was defined as a series of clicks separated by no more than 25 min from other clicks. This time frame was chosen to match potential gaps due to duty cycles, described in the next subsection. The start and end times of all encounters were noted, and these start and end times were used for further analysis. Custom
MATLAB (MathWorks) subroutines were developed to assist logging of encounters, and R (R Core Team version 3.2.2) was used for further statistical analysis.

We assumed no false positives (other signals mistaken for sperm whales) because all LTSA detections were visually verified by the analysts, and the variability between the 2 analysts was determined to be minimal by comparing their detections in data sets that both had examined independently. We also assumed negligible missed detections because the characteristics of sperm whale signals make them easy to distinguish from other species, and their frequency content and high amplitude are rarely masked (Worthington \& Schevill 1957, Watkins \& Schevill 1977, Gordon 1987, Goold 1999, Møhl et al. 2000, 2003, Madsen et al. 2002).

\subsection{Data analysis}

Given the broad geographic and temporal distribution of our passive acoustic data set (Figs. 1 \& 2), we selected a modeling framework for data analysis which allows testing of multiple spatial and temporal variables together, thereby providing a robust description of the patterns of sperm whale click detection across our data set. Statistical models are a common tool used to assess the relationships between cetacean presence and environmental forces (e.g. Becker et al. 2014, Moore \& Barlow 2014, Forney et al. 2015, Stanistreet et al. 2018, reviewed by Redfern et al. 2006). We did not seek one 'best' model but instead created several models using a variety of 
subsets of the detection data to fully explore relationships at different scales of time and space, with the goal of informing future study and conservation.

Models were built on several different spatial scales: all sites combined (All-sites), sites grouped into 4 subregions, and individual sites. The subregions consisted of the Main Hawaiian Islands (Hawai'i Island, Kauai, and Cross Seamount), the Northwestern Hawaiian Islands (Pearl and Hermes Reef, Ladd Seamount-Shallow, and Ladd Seamount-Deep), the Equatorial subregion (Palmyra Atoll-North, Palmyra Atoll-West, Kingman Reef, and Equator), and the Northern Mariana Islands (Saipan and Tinian). The spatial scale of these subregions is roughly 100 to $700 \mathrm{~km}^{2}$. Wake Atoll was not included in a subregion because it is remote from all other sites. At the smallest scale, all 13 sites were modeled individually.

Before models could be built, we had to account for varying duty cycles throughout the data set. With the goal of long-term monitoring of many species, some of the HARPs were set to record continuously, but because of the difficulty of reaching many of the remote sites, most of the instruments recorded using a duty cycle to extend battery life and data storage capacity. For consistency across the data set, all duty-cycled instruments recorded continuously for $5 \mathrm{~min}$ and then paused for 1 to 25 min until the next recording cycle. The most frequent sampling scheme that was common to all sites was $5 \mathrm{~min}$ of recording every $30 \mathrm{~min}$. Thus, the response variable used in our models was presence of sperm whale echolocation clicks in a randomly selected $5 \mathrm{~min}$ sample out of every $30 \mathrm{~min}$. Some data sets had only one $5 \mathrm{~min}$ sample per $30 \mathrm{~min}$, while others had up to 6 from which the sample to be used for modeling was randomly chosen. It is possible that there are false negatives (missed detections) because the duty cycling causes gaps in recording during which sperm whales could potentially pass through the detection area without being recorded. The effect of duty cycling was assessed by subsampling continuous data from 6 sites and comparing the detections between the continuous data and the subsampled data, as has been done with similar data sets (e.g. Stanistreet et al. 2018). Results from this assessment are presented in Section 3.3.

Once the standardized data sampling scheme of 5 min every 30 min was identified, we moved forward with our modeling using generalized additive models (GAMs) to assess patterns of sperm whale detection because these allow for the use of smoothing functions for relationships that cannot necessarily be described with linear terms. GAMs have frequently been utilized for investigating the relationship be- tween the environment and marine mammal presence (e.g. Forney 2000, Redfern et al. 2006, Becker et al. 2014, Forney et al. 2015). A typical GAM uses a simple identity covariance matrix, assuming all samples are independent. Preliminary exploration of our data revealed that sperm whale clicks were generally present for many hours or days at a time, followed by periods of hours or days with no detections. Such a pattern suggests temporal autocorrelation, with the detection of sperm whales in one 5 min sample increasing the likelihood of detection in subsequent 5 min samples. To reduce the impact of such temporal autocorrelation on the model output, the GAM smoothing functions were combined with generalized estimating equations (GEEs). GEEs utilize matrices other than the simple identity matrix to describe the covariance structure. Given the temporal autocorrelation in our data, the model error is best described using an autoregressive order 1 (AR-1) covariance structure, where the variance is homogeneous and the covariance between observations decreases exponentially as lag increases. To confirm this choice of covariance structure, the complete data set was modeled using multiple covariance structures, and the best model, selected by Akaike's information criterion (AIC), used the AR-1 covariance structure. GEE-GAM methods have previously been used successfully to examine a variety of marine mammal occurrence and response data (e.g. Panigada et al. 2008, Pirotta et al. 2011, Bailey et al. 2013, Booth et al. 2013, Stimpert et al. 2015). R packages MRSea (Scott-Hayward et al. 2013) and geepack (Højsgaard et al. 2006) were used.

In addition to examining the covariance structure before we began model selection, we also identified the best blocking structure to use in the GEE models. The size of the blocks, or panels, specifies which samples are likely to be autocorrelated, with samples outside of the block assumed to be independent from samples inside. The covariance matrices are then generated for individual blocks. We determined the ideal block size by consolidating the $5 \mathrm{~min}$ presence/absence data into bins of increasing size, from 1 to $15 \mathrm{~d}$, with sperm whale presence or absence reported for each bin. We then generated autocorrelation plots for each of the 15 binned data sets. A bin size of $12 \mathrm{~d}$ was found to be sufficient to account for the autocorrelation. To confirm the appropriateness of this bin size and to determine whether a standard GAM, without GEE, could account for the autocorrelation, we tested GAMs using detection data that had previously been consolidated into different sized bins ( 1 to $15 \mathrm{~d}$ ) and then checked the autocorrelation in the model residuals. The results confirmed that a 
$12 \mathrm{~d}$ bin size was appropriate to remove autocorrelation. However, by using simple GAMs with data binned by $12 \mathrm{~d}$, which results in only a single value of presence or absence in each $12 \mathrm{~d}$ period, we lost the resolution necessary to test for diel or lunar patterns. Therefore, we used GEE-GAMs, which allowed us to maintain the high temporal resolution of the $5 \mathrm{~min}$ samples while accounting for the strong temporal autocorrelation with 12 d panels, where each panel has its own covariance matrix and is assumed to be independent from all other panels.

To develop a best-fit model for each of the data sets, we used the MRSea library in R, described in detail in Scott-Hayward et al. (2013). We considered 6 predictor variables, including 3 continuous (date, day of the year, and lunar phase) and 3 categorical variables (geographic subregion, site, and diel phase), which are further explained in the next subsection. Because of multiple collinearities among the predictor variables, an automated step-wise approach for model selection could not be used; instead, all possible candidate models were created and considered, including a null model, and the model with the best fit was selected based on the quasi-likelihood information criterion with $\log (\mathrm{n})$ penalty (QICb). QICb was selected because GEEs are not based on full likelihood estimates; therefore, AIC could not be used, but QICb is appropriate (Pan 2001). For each data set, there were between 2 and 6 candidate models, based on which parameters were allowed for each spatial scale and which combinations of parameters could be used together while still avoiding collinearities. Each candidate base model was run through the spatially adaptive local smoothing algorithm (SALSA, Walker et al. 2011) using QICb to determine the best-fit smooth for the continuous predictors (lunar day, day of the year, and date). Within SALSA, maximum values for the splines of each continuous variable were set by the analyst to constrain the shape of the smooth and ensure that the results would be biologically interpretable. A maximum of 5 knots and a 1st degree polynomial fit was allowed for day of the year and lunar day, and a maximum of 3 knots and a 2nd degree polynomial fit was allowed for date.

The smooths obtained from SALSA for the continuous parameters were then used in combination with categorical parameters to generate GEEs with a binomial distribution for the response variable. The final model for each data set was selected based on QICb from all possible candidate models for that data set, each with different combinations of optimally smoothed, non-collinear parameters. The final GEE-
GAM model for each data set was validated by examining plots of cumulative residuals, which assess systematic over- or under-prediction; plots of COVRATIO statistics, which indicate the precision of the parameter estimates when individual blocks are omitted from the model; and PRESS (predicted residual error sum of squares) statistics, which indicate the sensitivity of the model predictions when individual blocks are removed. Marginal p-values from ANOVA were calculated for each parameter in the final GEE-GAM model using MRSea's built-in functions to provide a measure of the relative importance of each variable to the whole model. These marginal $p$-values were not used as the method for model selection; therefore, some parameters were retained in the best-fit model despite a non-significant marginal p-value.

The modeling process included 2 rounds of model generation. In round 1, we used model selection based on QICb, as described earlier in this subsection, to identify the most important parameters for each data set. In round 2, we ran descriptive models that included all the parameters that had been identified in round 1 as important, regardless of $\mathrm{QICb}$ value or statistical significance of each parameter for each individual data set. In other words, we ran all models in round 2 with the exact same set of parameters, regardless of whether that parameter was significant for that data set, and excluded the parameters that were not important in round 1 . These descriptive models helped us to further explore the relationship of sperm whale acoustic presence to those key parameters, regardless of any statistical significance.

\subsection{Covariate data}

Parameters representing a variety of spatial and temporal covariates were included as model predictor variables. The model based on the All-sites data included 2 categorical variables to assess spatial patchiness at different scales: geographic subregion and deployment site. Because these parameters were collinear, with individual sites belonging to just 1 subregion, the candidate models for the All-sites data were allowed to include only one or the other of these parameters. The site parameter was also included in the models of data from the subregions.

Within each model at all spatial scales, temporal trends were explored at 4 different scales: daily, lunar, seasonal, and multi-year. Daily changes in sperm whale detection rates were examined using a categorical diel parameter with 4 phases: night, 
dawn, day, and dusk. Although the low latitude of most of our monitoring locations tempers the effects of the changing seasons on daylight patterns, the exact timing of dawn, dusk, sunrise, and sunset does vary throughout the year at all of the sites. Therefore, we used a dynamic method for calculating the diel phase of each 5 min sample. Following the methods of Todd et al. (2009), the separation between the phases was calculated relative to sunrise, sunset, and the start and end of nautical twilight. Nautical twilight and sunrise/sunset information was collected from the US Naval Observatory (USNO) website (www.usno.navy.mil/USNO/) for the latitude and longitude of each deployment location. Diel phase was included in all of the base models in round 1 and in all of the explanatory models in round 2.

The impact of lunar cycles was tested by including a lunar day parameter. This was calculated based on the number of days from the previous new moon from USNO and was determined based on the latitude and longitude of each site. Lunar day was a continuous predictor with a cyclic cubic smooth that connected lunar day 1, the full moon, with lunar day 29 or 30 , just before the full moon. This parameter was included in all of the base models for All-sites, the subregions, and the individual sites that had recordings spanning more than $4 \mathrm{mo}$ to ensure sufficient monitoring throughout the lunar cycle. These sites included Cross Seamount, Hawai'i Island, Kauai, Palmyra Atoll-North, Palmyra Atoll-West, Pearl and Hermes Reef, Saipan, Tinian, and Wake Atoll. Additionally, a separate set of models was run for those same data sets using only the detections collected during nighttime to test for lunar trends that only impacted nighttime behavior. These nighttime-only models included all of the same parameters as the models with data from throughout the day, except the diel phase.

Seasonal patterns were explored by including a day of the year parameter as a candidate predictor variable. This continuous predictor was smoothed with a cyclic cubic smooth to reduce the impact of short-term (days to a few weeks) changes in detection rates and to allow the end of the year to be continuous with the start of the year. This parameter was not collinear with any other and was therefore tested for inclusion in the All-sites model and 3 of the subregions. This parameter was not included in models for the Equatorial subregion because highly uneven coverage at the different sites throughout the year could potentially mask or distort any real seasonal pattern. Seasonal patterns were also assessed at individual sites where data had been collected for at least $270 \mathrm{~d}$ of the year (all years combined). These sites included Cross Seamount,
Hawai'i Island, Kauai, Palmyra Atoll-West, Pearl and Hermes Reef, Saipan, and Tinian.

Long-term, multi-year trends were examined only at the Hawai'i Island site, where recordings spanned more than 7 yr. We included a continuous date parameter in the initial models and in the subsequent explanatory modeling. The date parameter was not included in subregion or All-sites models, despite longer-term monitoring at these larger spatial scales, because the composition of monitored sites changed over time, complicating the differentiation between long-term changes in detection rates and changes in site composition. The date parameter was fit with a quadratic b-spline, which reduced the potential for anomalous detection rates at the scale of weeks or months to mask the long-term trend.

\section{RESULTS}

\subsection{Duty cycle effects}

The effect of imposing a duty cycle on continuously sampled data varied by site, causing 8 to $23 \%$ of hours with sperm whale detections to be missed in subsampled data, and 0 to $21 \%$ of days with sperm whale detections to be missed in subsampled data. The average percentage of missed hours with detections within the subsampled data was $15 \%$, while the average percentage of missed days with detections was $9 \%$. Overall, the relatively low rate of missed hours and days with detections indicates that the likelihood of false negatives due to missed detections in duty cycled data is minimal but should not be considered insignificant.

\subsection{Overall detection rate}

We examined sperm whale detection rates at 3 spatial scales. Across the entire study region, sperm whales were detected at all of the sites (Fig. 1, Table 1), including the relatively shallow locations $(<400 \mathrm{~m})$ at Ladd and Cross seamounts. A total of 5061 full days were monitored across all of the sites, with sperm whales detected on $841 \mathrm{~d}$, for a total presence on $16.6 \%$ of days across the region. The highest total sperm whale detection rate was $18 \%$ of $5 \mathrm{~min}$ samples (Ladd Seamount-Deep), while the majority of the other sites had detections in fewer than $2 \%$ of 5 min samples (Fig. 1, Table 1). Subregions showed different rates of sperm whale presence, with the average detection rates ranging from $9.6 \%$ in the Northwestern Hawaiian Islands and $6.5 \%$ in the Northern 
Mariana Islands to $2 \%$ in the Main Hawaiian Islands and $<1 \%$ in the Equatorial subregion. At the smallest spatial scale, sites with higher detection rates were occasionally located near sites with low detection rates (e.g. 10-50 km apart), suggesting that sperm whale detection at any location may be less related to the larger geographic patterns identified in whaling data and more heavily influenced by local acoustic propagation and habitat variability. For example, sperm whales were detected in $1 \%$ of samples at Tinian compared to $12 \%$ at Saipan and in $2 \%$ of samples at Ladd Seamount-Shallow vs. $18 \%$ at Ladd Seamount-Deep. Despite the relatively short distance between some sites, no echolocation clicks were detected on more than 1 instrument, either because instruments were not deployed at both locations at the same time or the distance was too great for these signals to propagate.

\subsection{Model results}

Round 1 of modeling, where final models were selected from a suite of candidate models using QICb, revealed the importance of 4 parameters: site, diel phase, lunar phase, and day of the year. These initial models also uncovered consistent trends in the relationships with the site, diel phase, and day of the year parameters. The parameters that were selected for each final model and the marginal p-values are shown in Table 2. The final All-sites model included
3 parameters, all with low $\mathrm{p}$-values, indicating relatively high importance for all 3. These included site $(p<0.001)$, diel phase $(p=0.011)$, and day of the year $(\mathrm{p}<0.001)$ in the final model (Fig. 3).

The results from the final All-sites model, and the other final models identified in round 1 of modeling, informed round 2 of explanatory, descriptive modeling, where all models were run using the same sets of predictor variables, regardless of $\mathrm{p}$-value or $\mathrm{QICb}$ score. Diel phase was included in all of the descriptive models in round 2, while lunar phase, day of the year, and site were included in the descriptive models for data sets with sufficient coverage throughout the lunar month, throughout the year, or at multiple sites, respectively. The trends observed for each parameter for each data set in round 1 of modeling
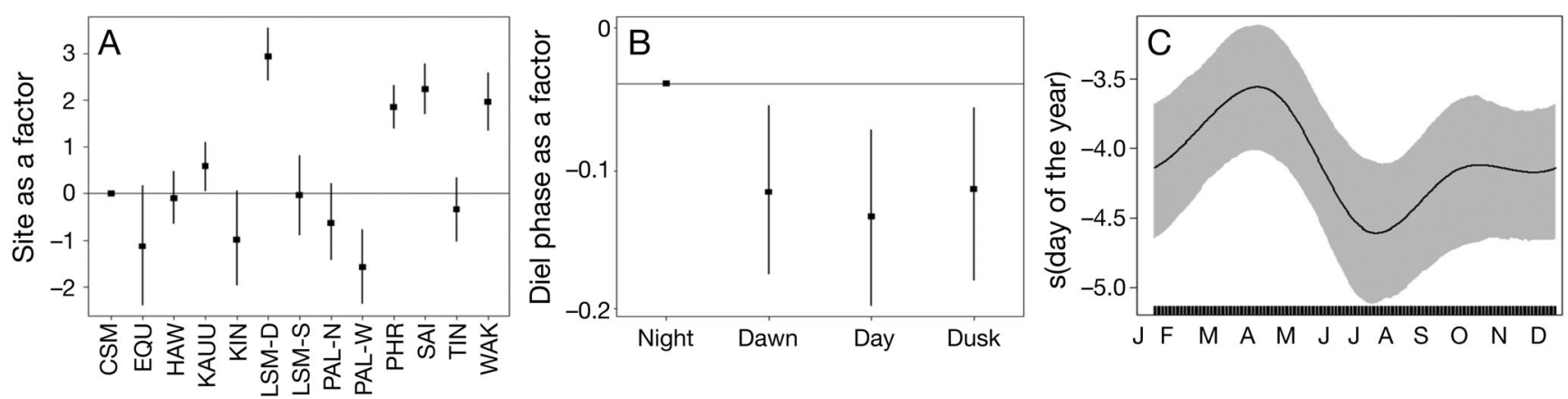

Fig. 3. Partial-fit plots for all data (All-sites combined) with parameters selected based on QICb. Parameters include (A) site, with high variability across all sites (abbreviations as in Fig. 1); (B) diel phase, with a nocturnal trend; and (C) month of the year, with a maximum in spring (April) and minimum in summer (July-August); months rather than days of the year are plotted here for ease of recognition; rug plot denotes effort. All plots include 95\% confidence intervals. Error bars for categorical variables (site, diel) are calculated relative to the first level, so there are no error bars for the first level 
were consistent with those seen in round 2, even if the models included slightly different predictor variables. Given this consistency, partial-fit plots are only shown for the explanatory models, where all parameters were included, to facilitate comparison of each parameter across all data sets (Figs. 3-6). The subregion parameter was not selected for a final model and is not discussed further.

\subsubsection{Site-by-site trends}

Consistent trends in sperm whale detection rates were observed across many of the models, even when comparing within and between different spatial scales. The importance of variability in site-bysite detection rates, which was noteworthy in the raw detection data, was also reflected in the model output. The site parameter was selected in 4 of 5 possible final models and was relatively important, as identified by low marginal p-values, in 3 of those 4 ( $p<0.001$, Table 2; All-sites, Northwestern Hawaiian Islands, and Northern Mariana Islands). The relative detection rates observed in the raw acoustic data were mirrored in the model output, with the highest detection rate seen at Ladd Seamount-Deep and the lowest rates in the Equatorial subregion, including Equator, Kingman Reef, and Palmyra Atoll-West (Figs. 1 \& 3).

\subsubsection{Diel trends}

In round 1 of model selection, the diel parameter was selected in 5 of 18 models, indicating minor importance across the region (Table 2, Figs. $3 \& 4$ ). However, in those 5 models, there was a consistent nocturnal trend, with the nighttime phase always having the highest detection rate and the daytime phase usually having the lowest (e.g. Fig. 3). In round 2, the trends were less consistent, with a nocturnal trend present in 12 models but either no trend (Equatorial subregion, Equator site) or a diurnal pattern (Palmyra Atoll-West, Palmyra Atoll-North, Ladd Seamount-Shallow, Wake Atoll) in the other 6 models.

\subsubsection{Lunar trends}

The lunar parameter was revealed to be moderately important in the variability of sperm whale detections across the region. This parameter was retained in 8 of 14 possible models in round 1 of model selection when the data from throughout the day was used and in 7 of the 14 possible models when looking only at data from the nighttime. However, the actual trends observed in the partial-fit plots were so disparate that there is no consistent pattern at any spatial scale (Fig. 5).

\subsubsection{Seasonal trends}

A consistent seasonal pattern was evident in 9 of 11 possible models (Figs. 3 \& 6; All-sites, Northern Mariana Islands subregion, Main Hawaiian Islands subregion, Northwestern Hawaiian Islands subregion, Saipan, Cross Seamount, Hawai'i Island, Kauai, and Pearl and Hermes Reef). All of these models included a minimum detection rate in the summer (July-September) in most models. Seven models also included a maximum detection rate in mid-spring (MarchMay): all of those listed above except Cross Seamount, which had a maximum in winter (January). The 2 exceptions to the summertime minimum were both data sets where the day of the year parameter was not included in the final model from round 1 of modeling and for which the best-fit model was actually the null model: Tinian and Palmyra Atoll-West. At Tinian, there was a maximum in late spring (May) and a minimum in the fall (October-November), while at Palmyra Atoll-West, the seasonal trend was roughly opposite of the majority of the other data sets, with a maximum in mid-summer (June-July) and minima in both the early spring (March) and early fall (September).

\subsubsection{Long-term trends}

The date parameter was not retained in the round 1 final model for Hawai'i Island, indicating relatively weak importance of long-term trends in explaining the variability in sperm whale detections at this site for this data set. Exploratory modeling revealed an overall decline throughout the time series, with a possible secondary peak in 2012 (Fig. 7).

\section{DISCUSSION}

This expansive data set has allowed us to undertake the longest passive acoustic study of sperm whales yet. This study has generated insights into the temporal and geographic patterns in sperm whale occurrence in the central and western North Pacific, highlighting subtle patterns of temporal variability 

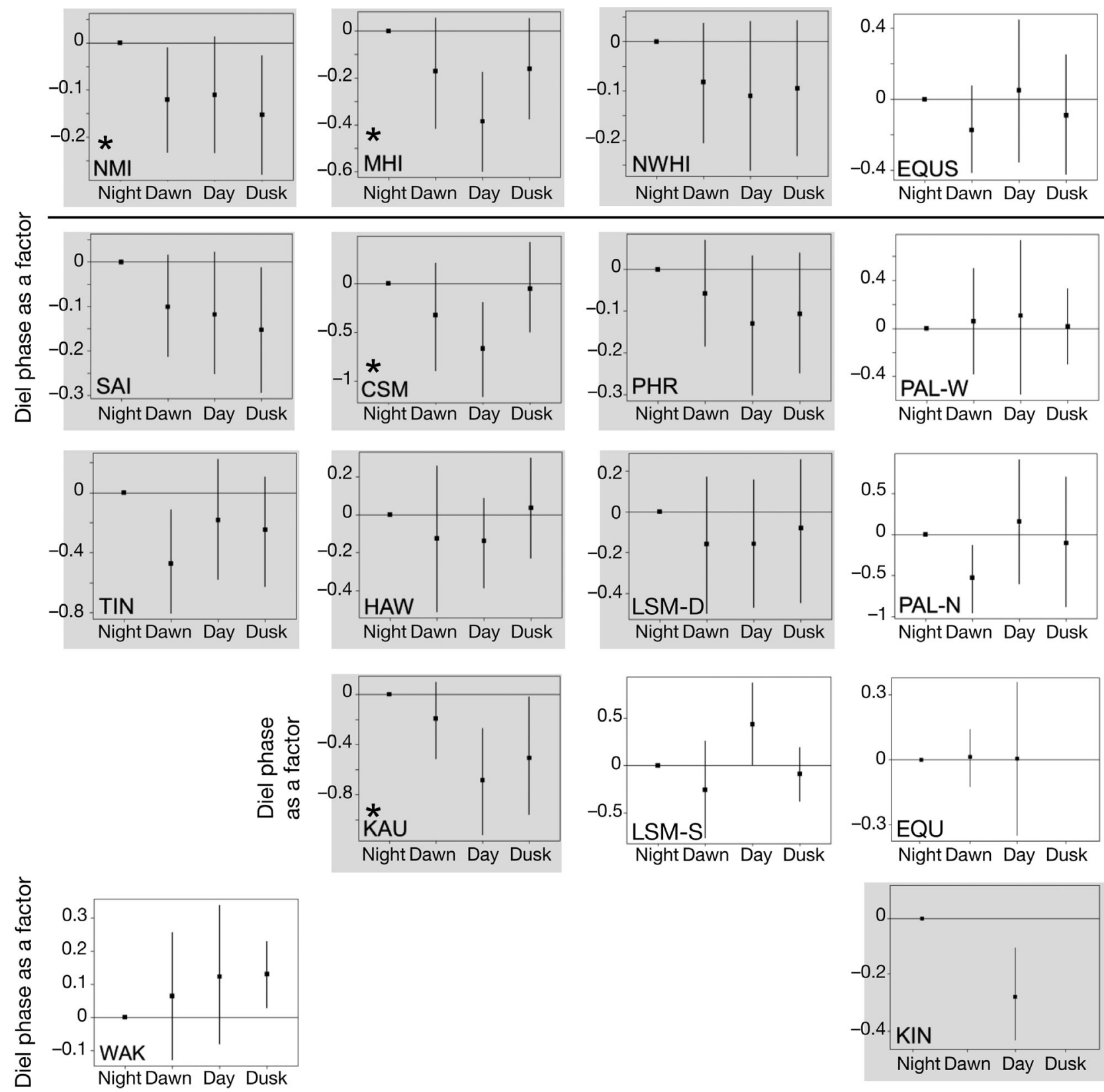

Fig. 4. Diel patterns for 17 data sets, including subregions (top panels, above line) and all individual sites (below line). Individual plots below the line are in columns indicating the subregion to which they belong (e.g. SAI and TIN are in the column below the NMI subregion). WAK is not included in a subregion and therefore the plot has been separated from the other sites. The same layout is used in Figs. 4, 5 and 6 to facilitate comparison. Site abbreviations as in Fig. 1. The $y$-axis is the modeled partial fit for each diel phase as a factor level. All plots include $95 \%$ confidence intervals. Error bars for categorical variables are calculated relative to the first level, so there are no error bars for the first level. Asterisk ${ }^{*}$ ) indicates parameter was selected for final model of round 1 of modeling. Gray fill indicates nocturnal trend

across multiple time scales and high spatial variability. Sperm whales were detected at all of the sites, with a dominant seasonal trend revealing lower detections during the summer and early fall as well as a less pronounced nocturnal pattern. At smaller spatial scales, the patterns are more nuanced, varying by subregion and site. Using the explanatory models developed here, we can begin to explore in detail the relationships between the predictor variables and sperm whale acoustic activity.

The acoustic activity of sperm whales was generally low across the region, in contrast to our expectations 

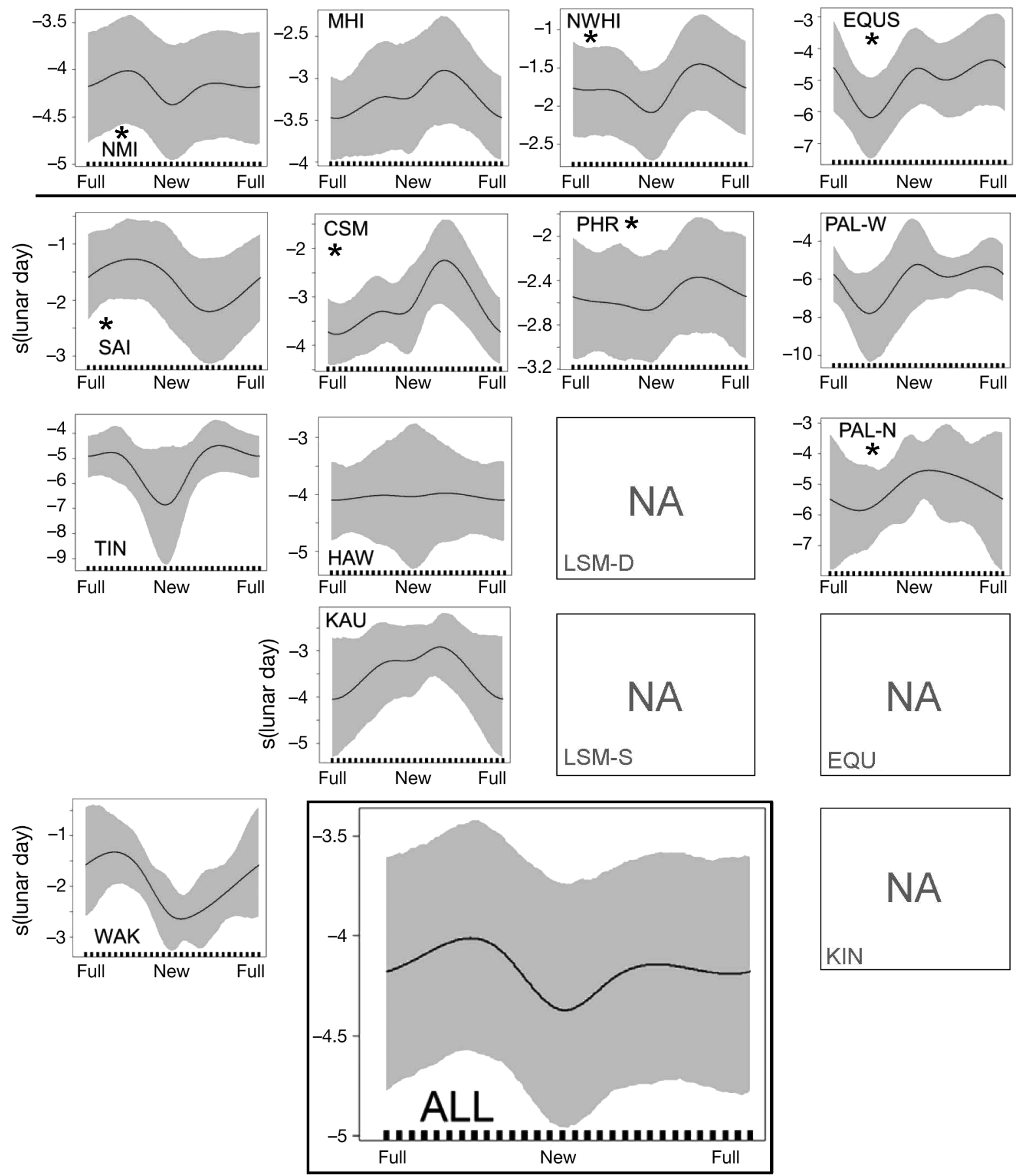

Fig. 5. Lunar patterns for 14 data sets with more than 4 mo of data, including subregions (top panels, above line) and all individual sites (below line). For an explanation of the figure layout see Fig. 4. Site abbreviations as in Fig. 1. Rug plots (at bottom of graphs) denote effort. The $y$-axis is the partial-fit smooth function of the lunar day. All plots include $95 \%$ confidence intervals (gray regions). Asterisk $\left({ }^{*}\right)$ indicates parameter was selected for final model of round 1 of modeling. NA indicates there was not sufficient data $(<4 \mathrm{mo})$ to model lunar trends

of relatively high abundance based on historical whaling catch data (Smith et al. 2012, Mizroch \& Rice 2013) and more recent line-transect surveys (Barlow \& Taylor 2005, Fulling et al. 2011, Hill et al. 2013,
Bradford et al. 2017). All monitoring sites were considered as potentially good sperm whale habitat (e.g. deep water, close to islands and seamounts, Fulling et al. 2011, Forney et al. 2012, 2015); however, sperm 

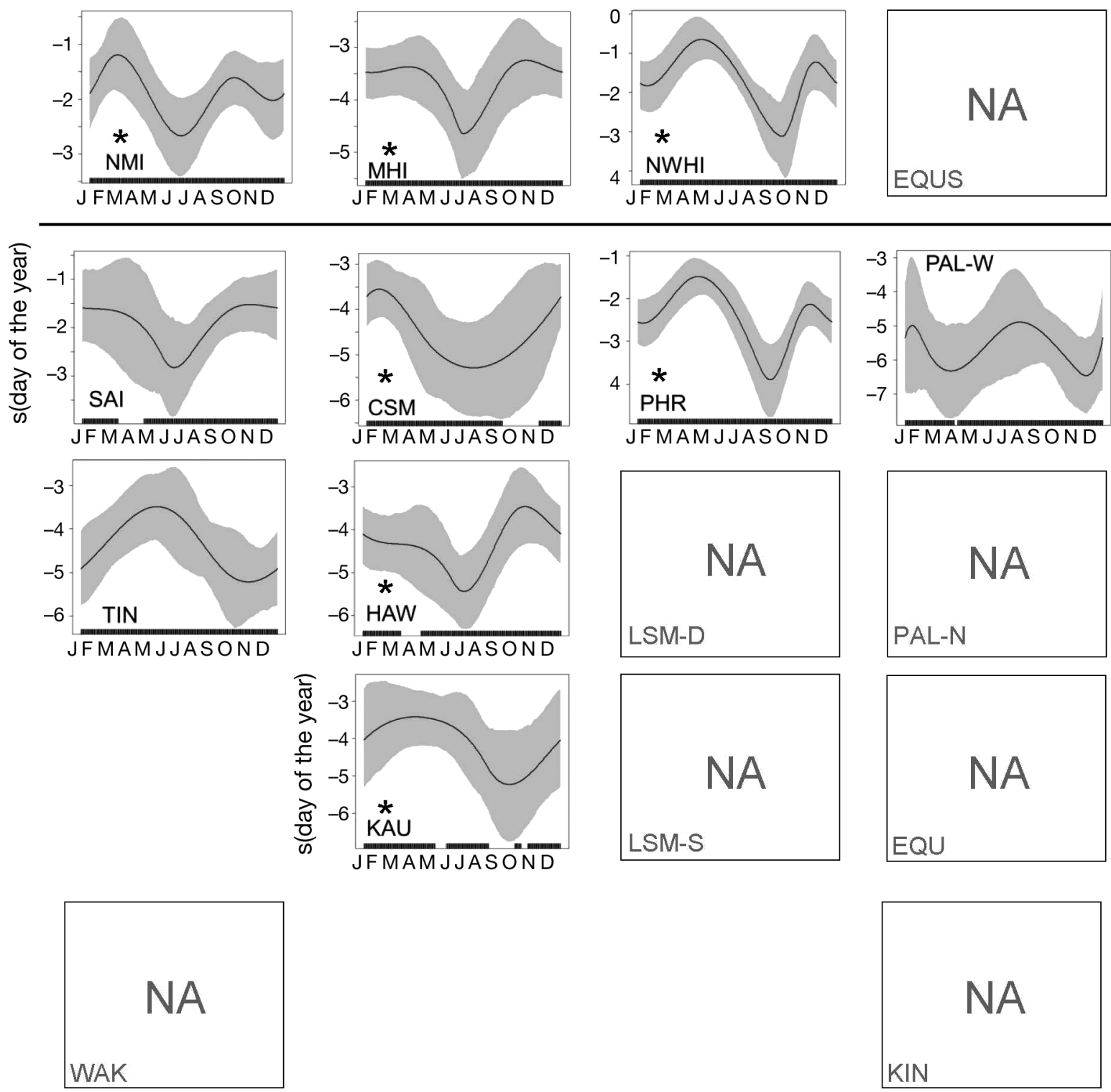

Fig. 6. Seasonal trends for 11 data sets with data from at least $270 \mathrm{~d}$ of the year, including subregions (top panel, above line) and all individual sites (below line). For an explanation of the figure layout see Fig. 4. Site abbreviations as in Fig. 1. Rug plots (at bottom of graphs) denote effort. The $y$-axis is the partial-fit smooth function of the day of the year. All plots include $95 \%$ confidence intervals (gray regions). Asterisk $\left({ }^{*}\right)$ indicates parameter was selected for final model of round 1 of modeling. NA indicates there was not sufficient data $(<270 \mathrm{~d}$ of the year) to model seasonal trends. There is no plot from EQUS because of uneven seasonal coverage at the different sites

whales were detected in fewer than $3 \%$ of 5 min samples in two-thirds of our sites. Low acoustic activity overall is unlikely to be due to migrations or dynamics in acoustic behavior, as the females and young animals that dominate the tropical and subtropical waters are not known to undergo regular migrations (Whitehead 2003), and they spend approximately 75 to $80 \%$ of their time engaging in foraging (using echolocation clicks) throughout the year (Whitehead
\& Weilgart 1990, 1991, Whitehead 2003). Additionally, groups of sperm whales, which tend to coordinate movements over the scale of days to months (Best 1979 in Whitehead 2003), move at relatively slow speeds (approximately 1-5 knots) and often spread out over $1 \mathrm{~km}$ or more when foraging (Whitehead 2003). Given this slow travel speed and spread, each group could spend several hours or days within the detection range of a HARP, depending on sound prop- 


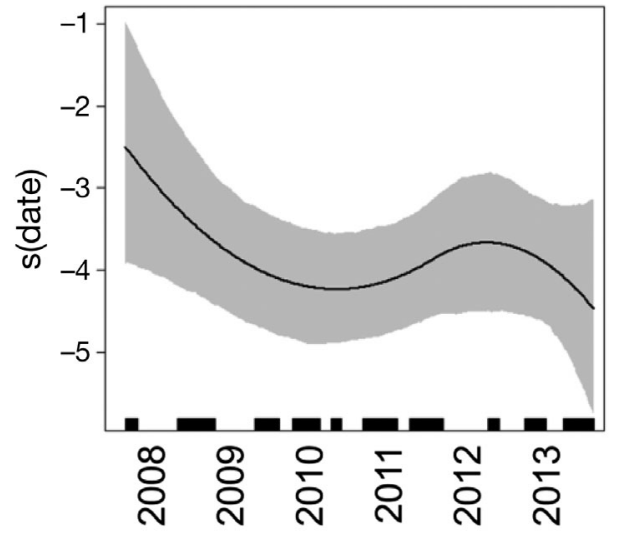

Fig. 7. Partial-fit plot for date parameter at Hawai'i Island, suggesting a possible long-term decline in detections. The $y$ axis is the partial-fit smooth function of the date; rug plot denotes effort. Gray region indicates $95 \%$ confidence intervals

agation and foraging success (Whitehead \& Weilgart 1991, Whitehead 2003), which provides ample opportunity for being recorded and detected. Perhaps the best explanation for the low detection rates at many of our sites is that the distribution of sperm whales across the North Pacific Ocean is quite patchy, which is not reflected in the large-scale, long-term assessments from whaling data or rapid, snapshot-like ship-based line-transect surveys conducted in modern times. Our data allow for a more nuanced picture of how sperm whale behavior may vary between subregions and individual sites.

The large variability in detection rates across all of our sites, and particularly at some pairs of closely located sites (e.g. presence in $12 \%$ of 5 min bins at Saipan vs. $1 \%$ at Tinian, separated by approximately $44 \mathrm{~km})$, likely reflects patchiness in sperm whale distribution, even within areas where we expected high abundance based on historic whaling data and modern surveys. Similar patchiness has been documented in other regions using passive acoustics, including in the Gulf of Alaska and the western North Atlantic (Mellinger et al. 2004, Stanistreet et al. 2018), areas of a comparable spatial scale to our subregions, with some sites having notably higher detection rates than others in the same general area. One possible explanation is that sperm whale prey, including deep-water squids and fishes, are likely to be distributed patchily across the region (e.g. Clark et al. 2010, McClain \& Hardy 2010), and their patchiness is then reflected in the distribution of the sperm whales. Another possibility is that sperm whales are responding to small and mesoscale oceanographic features that are not uniformly distributed across the region. In the Gulf of Mexico, for example, sperm whales are known to concentrate in or around mesoscale eddies that form regularly and move across the basin (Griffin 1999, Baumgartner et al. 2001). Similar oceanographic features are also common in the North Pacific, particularly around the Hawaiian Islands, where mesoscale eddies form regularly and have a measurable impact on the local food chain, from phytoplankton (Seki et al. 2001, Vaillancourt et al. 2003) up to top predators (Seki et al. 2002). These features tend to increase primary productivity and/or shift phytoplankton community composition in or around the eddy by increasing nutrient flux into the photic zone, with an end result of more abundant prey for top predators (Seki et al. 2002). Such predators, including sperm whales, may follow the transient features as they move across the ocean (e.g. Griffin 1999, Baumgartner et al. 2001, Seki et al. 2001), and because the eddies are relatively small in scale ( 100 km diameter, Rhines 2001), their presence in a subregion could lead to a patchy distribution of top predators.

At the shallowest sites, the low detection rates may reflect sperm whale preference for deeper habitats. Most recording sites were deep on the slopes of islands or seamounts; however, the HARPs at Cross Seamount and Ladd Seamount-Shallow were placed at shallower depths (397 and $117 \mathrm{~m}$, respectively). Since sperm whales are deep divers that forage in deep water (Watwood et al. 2006), it is less likely that they would be close to these shallower sites, and it is also less likely that their echolocation clicks would propagate from more distant deep waters up to the shallower hydrophones (Richardson et al. 1995).

Turning from overall spatial patterns to more detailed analyses, the models developed here allow us to further explore the environmental forces impacting sperm whale presence in the region by helping to answer the question 'What is the relationship between each of our models' parameters and the detection of sperm whales' acoustic signals?' While our first round of modeling guided us to identify the parameters with the greatest importance for the majority of data sets, round 2 allowed further exploration of those parameters for all data sets. This process differs from many predictive modeling efforts, which seek only to identify the best-fit model for a given data set. By instead using a descriptive process, we can examine the patterns of each parameter in all of our data sets, even when those parameters were not selected for a final best model. Through this process, we identified parameters that were important (diel phase, lunar phase, day of the year, site) 
and those that were not (subregion and date) and then further explored the relationship with the important parameters.

For many animal species, daily activity levels and behaviors, including sound production, fluctuate over a $24 \mathrm{~h}$ period, with most species falling into categories of being nocturnal, diurnal, or crepuscular. Previous studies of sperm whales have found no consistent diel pattern in diving behavior or acoustic behavior and no clear explanation for the trends that were observed (e.g. Papastavrou et al. 1989, Watkins et al. 1999, 2002, Amano \& Yoshioka 2003, Aoki et al. 2007, Davis et al. 2007, Hodge et al. 2013, Stanistreet et al. 2018). Our models indicate that the influence of diel phase on sperm whale acoustic detection in the North Pacific is minor, with this parameter being included in only one-quarter of the final models from round 1 of modeling. However, there was a strong nocturnal trend, with increased nighttime detections in two-thirds of the data sets in round 2 of explanatory modeling. Additionally, a geographic pattern was suggested, with the diel phase parameter not being included in any of the final models from round 1 for the Equatorial subregion and the nocturnal trend only being observed in 1 of 5 data sets from that area in round 2 of modeling (Kingman Reef).

The increase in nighttime detections of sperm whale acoustic signals at many locations indicates a change in sperm whale behavior and/or proximity to the HARPs on a daily cycle. The simplest explanation is that because echolocation clicks are used primarily for foraging (Jaquet et al. 2001, Watwood et al. 2006), an increase in detections of those clicks at night is due to an increase in foraging behavior at night. Such an increase has been shown in other locations in previous studies based on gut content analysis and dive patterns (Matsushita 1955, Watkins et al. 1999, Aoki et al. 2007). The question of why sperm whales might be feeding more at night is not as easily answered. One explanation is that many squids, sperm whales' primary prey, undergo diel vertical migration, where the squid are nearer to the surface at night and at depth during the day (e.g. Gilly et al. 2006, Watanabe et al. 2006). This may lead to changes in the availability of the squid to sperm whales or changes in the foraging technique used by sperm whales at different times of the day. For example, sperm whales have been shown to track the vertical movements of jumbo squid in the Gulf of California (Davis et al. 2007), spending more time in shallower depths at night. Similarly, in habitats near seamounts and islands, this daily migration of prey species may also include a horizontal component (e.g. Benoit-Bird \& Au 2003, Gilly et al. 2006), which could draw sperm whales beyond the detection range of the HARPs during the day. The increase in nocturnal acoustic detections of sperm whales described here may indicate that in some locations, perhaps for particular prey, it is more energetically efficient for sperm whales to forage at night.

Despite the dominant nocturnal trend in the models from round 2, there were still 5 data sets (of 17) that showed an opposite diurnal pattern and 1 that had constant detection rates across all diel phases (Equator). Further, the first round of modeling did not select for the diel parameter in 6 of 11 of the data sets. This inconsistency indicates that there is some plasticity or variability in the diel activity of sperm whales across the region that we cannot yet explain. Similar variability in acoustic activity in different diel phases across sites has been observed for sperm whales in other regions globally (e.g. Amano \& Yoshioka 2003, Aoki et al. 2007, Merkens 2013, Stanistreet et al. 2018). Some possible explanations include differences in diel behavior based on social group or population, age, sex, season, or simply high levels of individual variability. This has been observed in other odontocete species. For example, different click types predominated during day and night for Pacific white-sided dolphins Lagenorhynchus obliquidens at different sites in the Southern California Bight, which may indicate the presence of different populations and perhaps different prey species (Soldevilla et al. 2010). The diel patterns in acoustic presence of harbor porpoises Phocoena phocoena in the Baltic Sea varied seasonally and across different sites (Brandt et al. 2014, Schaffeld et al. 2016) and have been shown to vary strongly between individuals (Linnenschmidt et al. 2013). Thus, a full explanation of the variability in sperm whale diel behavior depends on an enhanced understanding of the demographics, prey preferences, and movements of sperm whales.

In contrast to the consistent nocturnal trends, the relationship between sperm whale detections and lunar cycles was highly variable. The lunar day parameter was included in more than half of the final models; however, the patterns in those data sets, and in the subsequent explanatory models, were different across all models, with no clear trends discernable at any spatial scale. Additionally, the marginal $\mathrm{p}$-values from round 1 of modeling were much higher for the lunar parameter than all other parameters in the final models except for Cross Seamount $(p=0.006$, Table 2$)$. Within each 
model, the patterns were consistent whether we modeled the data from all times of day or just the detections from the nighttime, suggesting that lunar cycling could impact sperm whale behavior at all times of the day. There has been no previous research on the relationship between lunar cycles and sperm whale activity, and research on effects of lunar cycle on other cetaceans is sparse. Previous researchers found increased abundance of 2 dolphin species on feeding grounds during the full moon, although they did not monitor echolocation signals, so it is unknown whether echolocation rates changed with animal abundance (Benoit-Bird et al. 2009). Others found decreased echolocation in common dolphins Delphinus delphis when there was increased lunar light at the sea surface (Simonis et al. 2017). Researchers have shown that the vertical migration of dolphin prey is reduced during the full moon (Roper \& Young 1975, Schaefer \& Fuller 2002, Benoit-Bird et al. 2009), and there are multiple hypotheses that may explain the relationship between reduced prey availability and odontocete activity, which will not be expanded on here. In contrast to surface-feeding dolphins, sperm whales are deep diving and feed on deep-living organisms, and our results suggest that sperm whale detection rates are generally not related to lunar illumination. It is unclear how changes in light at the surface could affect the foraging behavior of deep-diving predators (Watwood et al. 2006), although it has been shown that even the subtle changes in light due to lunar cycles are detectable in the vertical migration behavior of animals at depths below 1000 $\mathrm{m}$ (Ochoa et al. 2013). The ultimate cause for the relationship (or lack of relationship) between lunar cycles and sperm whale detection rates cannot be determined using the available data.

A common seasonal trend was revealed, including an increase in detections in the spring and a decrease in the summer or fall, and this was observed throughout the entire central and western North Pacific (Figs. $3 \& 6$ ). Further, the seasonal trend had a predictable geographic trend in the central North Pacific, with minimum detection rates occurring later in the year at more northerly sites. This suggests that animals may be moving north along the Hawaiian archipelago or out of the study area as the summer progresses. This consistent seasonal pattern contrasts with the varying trends in seasonality observed in previous passive acoustic monitoring efforts (Mellinger et al. 2004, Laran \& Drouot-Dulau 2007, Hodge 2011, Merkens 2013, Wong \& Whitehead 2014, Giorli et al. 2015, 2016, André et al. 2017,
Stanistreet et al. 2018). The lack of consistent patterns in previous studies may be due to relatively short monitoring times, which generally ranged from a few months to at most a few years. We observed strong year-to-year variability in seasonality of detections, such that long-term seasonal trends may be obscured in data sets that span no more than 2 or $3 \mathrm{yr}$. Two other sources of sperm whale data, historic whaling records and modern visual observations, do sometimes span many years and have revealed multiple locations where sperm whales are found yearround (e.g. Clarke 1957, Oshumi 1966, Kasuya \& Miyashita 1988, Whitehead 2003, Jochens et al. 2008, Smith et al. 2012, Johnson et al. 2016); however, despite the longer duration, these data sets also lack the power to detect seasonal trends due to the difficulty of sampling in rough, winter weather. The seasonality reported in the current study may be associated with geographic shifts in the population or changes in the composition of the population that have previously gone undetected due to sampling designs that would have had little power to detect a seasonal signal.

The seasonal patterns we observed in sperm whale acoustic activity may be connected to the demographic composition of sperm whale populations in the region. Males are believed to move between lower and higher latitudes throughout adulthood (Whitehead 2003), and movements of males and females in the North Pacific have been shown with Discovery and satellite tags to be on the scale of hundreds to thousands of kilometers (Jochens et al. 2008, Mizroch \& Rice 2013, Straley et al. 2014, Baird 2016). The seasonal pattern of sperm whale detections shown here suggests seasonal movement of sperm whales on this same temporal and spatial scale. To track the composition of a sperm whale population over time, the presence of male sperm whales in a passive acoustic record could be assessed by looking for slow clicks (clangs) in the data, which are signals that are only produced by adult males (Weilgart \& Whitehead 1988), or by measuring the inter-click interval, which is shorter for females (closer to $0.5 \mathrm{~s}$ ) than for males (closer to $1 \mathrm{~s}$ ) (Goold \& Jones 1995, Solsona Berga 2019). It may also be possible to estimate the general size class of individual animals, and hence their sex, from the inter-pulse intervals of the recorded clicks (Gordon 1991, Solsona Berga 2019), although recent research has suggested that using this information to repeatedly identify specific individuals has limited reliability (Bøttcher et al. 2018). Applying these methods to the current data set is beyond the scope of this project but would help 
determine whether the seasonal trend is related to a demographic segment of the population leaving the region.

Sperm whales are listed as Endangered globally, but the populations in the central and western North Pacific are not as closely monitored as in some other locations (e.g. Notarbartolo di Sciara et al. 2012, Moore \& Barlow 2014). The current population size for the whole North Pacific is unknown, but the best estimates for sperm whale population sizes in subregions are $4559(\mathrm{CV}=0.33)$ for the Hawaiian Islands exclusive economic zone based on visual sightings (Bradford et al. 2017) and $26300(\mathrm{CV}=0.81$ ) or 32100 $(\mathrm{CV}=0.36)$ for a portion of the eastern temperate North Pacific based on visual sightings or acoustic detections, respectively (Barlow \& Taylor 2005). However, the most recent of these estimates was based on data collected more than 8 yr ago (in 2010, Bradford et al. 2017). Therefore, it is important to consider possible changes in detections over a longer time scale at the site with the longest data set. Other assessments of sperm whale population trends in the Pacific using visual survey data have found little or no long-term trend (Taylor et al. 2008, Moore \& Barlow 2014). The date parameter was not selected for inclusion in the final model at Hawai'i Island, which indicates that this parameter does not help to account for much of the variability in sperm whale detections at that site. Explanatory modeling revealed a negative trend in detection rate over time (Fig. 7). Inclusion of additional years of data in future analyses focused on long-term patterns at this site may inform whether there is truly a decline in sperm whale acoustic activity in this area and if the downward trend in detection rates is related to other factors, such as the major oceanographic cycles that might impact abundance and distribution of marine mammals in this region (e.g. El Niño-Southern Oscillation, Pacific Decadal Oscillation) (Francis et al. 1998, Jaquet et al. 2003, Calambokidis et al. 2009, Salvadeo et al. 2015, Fleming et al. 2016).

As important as it is to identify predictor variables that can reveal information about our target species, it is also essential to recognize when a set of predictor variables does not help to explain the observed trends. In round 1 of model selection, there were 2 sites where the final model selected was the null model: Palmyra Atoll-West and Tinian. This lack of statistical relationship indicates that the variables we provided simply do not explain the trends in sperm whale acoustic activity for these data sets. Based on the subsequent explanatory modeling, we can determine that the patterns seen in the relationships with those predictor variables are similar to what is observed at other sites across the North Pacific, but those parameters simply do not provide enough explanatory power to offset the cost of including them in the model. Further data collection or introducing other predictor variables will be necessary to gain a full understanding of the sperm whale acoustic activity at these sites.

Some limitations are present in this study. Most importantly, the data represent sperm whale detection rates at 13 discrete monitoring locations scattered across the vast central and western North Pacific Ocean. Each of these locations was chosen to be similar to the other sites, including being suitable habitat for deep-diving cetaceans, being close to an island or atoll, and enabling deployment of acoustic recorders at comparable depths (550-1300 m, except 2 sites, discussed below). This similarity across sites should result in similar detection ranges throughout the data set, but it does not give information about sperm whale presence in deep water over the abyssal plane where many sperm whales likely spend most of their lives (Whitehead 2003). The large differences in detection rates between instruments placed at slightly different sites in 1 area (e.g. Ladd Seamount-Shallow at $117 \mathrm{~m}$ vs. Ladd Seamount-Deep at $1092 \mathrm{~m}$ ) emphasize the importance of instrument placement, confirming that despite their cosmopolitan distribution, sperm whales cannot be detected in all marine environments, particularly when considering depths less than $1 \mathrm{~km}$. Additionally, we cannot distinguish between periods of silence when animals are present but not vocalizing and periods of silence when animals have moved beyond the range of the instrument. The inability to distinguish these behaviors (or to know the proportion of time spent vocalizing) is a critical component that prevents us from applying these data to density or abundance estimates at this time. And, finally, although this data set as a whole spans a remarkable $8.5 \mathrm{yr}$, the majority of sites were monitored for less than $2 \mathrm{yr}$, which is short relative to the life span of the sperm whale, which is likely underestimated at 60 to $70 \mathrm{yr}$ (Whitehead 2003). A few years is also short relative to the temporal scale of environmental changes that may impact the distribution of sperm whales across such a broad area. This limited duration makes it difficult to assess long-term changes in local populations, particularly given the dynamic nature of the local ocean environment and the possible impact of large-scale phenomena such as the El Niño-Southern Oscillation and Pacific Decadal Oscillation. 
Acknowledgements. Countless people have been involved with the development, deployment, recovery, and data processing of the HARPs, and we thank them heartily for their efforts, particularly the members of the Scripps Whale Acoustics Lab and Scripps Acoustic Ecology Lab as well as the technicians and field staff of the Pacific Islands Fisheries Science Center. We acknowledge the assistance of the officers and crews of the NOAA ships 'Sette' and 'Hi'ialakai' as well as other ships of opportunity for deployments and recoveries at multiple locations. Deployments and recoveries at the Hawai'i Island site were also made possible by the efforts of Robin Baird, Daniel Webster, Greg Schorr, and Dan McSweeney. HARP deployments at Palmyra Atoll were possible through the cooperation and assistance of The Nature Conservancy, the Palmyra Atoll Research Consortium, and the US Fish and Wildlife Service. We also express deep thanks to Danielle Harris and Amanda Bradford for invaluable discussion and assistance with statistical analysis. Funding for HARP deployment and analysis has been provided by the Protected Species and Ecosystems and Oceanography divisions at NMFS PIFSC, the Ocean Acoustics Program at NMFS Office of Science and Technology, the US Navy CNO-N45 and Pacific Fleet. HARP deployments at Palmyra Atoll were conducted under USFWS Special Use permit 12533, and deployments at Pearl and Hermes Reef and Ladd Seamount within the Papahanaumokuakea Marine National Monument were conducted under permits PMNM-2008-020 and PMNM-2010-042.

\section{LITERATURE CITED}

Amano M, Yoshioka M (2003) Sperm whale diving behavior monitored using a suction-cup-attached TDR tag. Mar Ecol Prog Ser 258:291-295

André M, Caballé A, van der Schaar M, Solsona A and others (2017) Sperm whale long-range echolocation sounds revealed by ANTARES, a deep-sea neutrino telescope. Sci Rep 7:45517

Aoki K, Amano M, Yoshioka M, Mori K, Tokuda D, Miyazaki N (2007) Diel diving behavior of sperm whales off Japan. Mar Ecol Prog Ser 349:277-287

* Bailey H, Corkrey R, Cheney B, Thompson PM (2013) Analyzing temporally correlated dolphin sightings data using generalized estimating equations. Mar Mamm Sci 29:123-141

Baird RW (2016) The lives of Hawai'i's dolphins and whales: natural history and conservation. University of Hawai'i Press, Honolulu, HI

Barlow J, Taylor BL (2005) Estimates of sperm whale abundance in the northeastern temperate Pacific from a combined acoustic and visual survey. Mar Mamm Sci 21: 429-445

Baumgartner MF, Mullin KD, May LN, Leming TD (2001) Cetacean habitats in the northern Gulf of Mexico. Fish Bull 99:219-239

Becker EA, Forney KA, Ferguson MC, Foley DG, Smith RC, Barlow J, Redfern JV (2010) Comparing California Current cetacean-habitat models developed using in situ and remotely sensed sea surface temperature data. Mar Ecol Prog Ser 413:163-183

* Becker EA, Forney KA, Foley DG, Smith RC, Moore TJ, Barlow J (2014) Predicting seasonal density patterns of California cetaceans based on habitat models. Endang Species Res 23:1-22

Benoit-Bird KJ, Au W (2003) Prey dynamics affect foraging by a pelagic predator Stenella longirostris over a range of spatial and temporal scales. Behav Ecol Sociobiol 53: 364-373

* Benoit-Bird KJ, Dahood AD, Würsig B (2009) Using active acoustics to compare lunar effects on predator-prey behavior in two marine mammal species. Mar Ecol Prog Ser 395:119-135

* Booth CG, Embling C, Gordon J, Calderan SV, Hammond PS (2013) Habitat preferences and distribution of the harbour porpoise Phocoena phocoena west of Scotland. Mar Ecol Prog Ser 478:273-285

* Bøttcher A, Gero S, Beedholm K, Whitehead H, Madsen PT (2018) Variability in the inter-pulse interval in sperm whale clicks with implications for size estimation and individual identification. J Acoust Soc Am 144:365-374

* Bradford AL, Forney KA, Oleson EM, Barlow J (2017) Abundance estimates of cetaceans from a line-transect survey within the U.S. Hawaiian Islands exclusive economic zone. Fish Bull 115:129-142

* Brandt MJ, Hansen S, Diederichs A, Nehls G (2014) Do manmade structures and water depth affect the diel rhythms in click recordings of harbor porpoises (Phocoena phocoena)? Mar Mam Sci, 30:1109-1121

* Calambokidis J, Barlow J, Ford JKB, Chandler TE, Douglas AB (2009) Insights into the population structure of blue whales in the eastern North Pacific from recent sightings and photographic identification. Mar Mamm Sci 25: 816-832

Clark MR, Althaus F, Williams A, Niklitschek E and others (2010) Are deep-sea demersal fish assemblages globally homogenous? Insights from seamounts. Mar Ecol 31: $39-51$

Clarke R (1957) Sperm whales of the Azores. Discov Rep 28: 237-298

* Davis RW, Jaquet N, Gendron D, Markaida U, Bazzino G, Gilly W (2007) Diving behavior of sperm whales in relation to behavior of a major prey species, the jumbo squid, in the Gulf of California, Mexico. Mar Ecol Prog Ser 333:291-302

*Fleming AH, Clark CT, Calambokidis J, Barlow J (2016) Humpback whale diets respond to variance in ocean climate and ecosystem conditions in the California Current. Glob Chang Biol 22:1214-1224

Forney KA (2000) Environmental models of cetacean abundance: reducing uncertainty in population trends. Conserv Biol 14:1271-1286

Forney KA, Ferguson MC, Becker EA, Fiedler PC and others (2012) Habitat-based spatial models of cetacean density in the eastern Pacific Ocean. Endang Species Res 16: 113-133

Forney KA, Becker EA, Foley DG, Barlow J, Oleson EM (2015) Habitat-based models of cetacean density and distribution in the central North Pacific. Endang Species Res 27:1-20

Francis RC, Hare SR, Hollowed AB, Wooster WS (1998) Effects of interdecadal climate variability on the oceanic ecosystems of the NE Pacific. Fish Oceanogr 7:1-21

Fulling GL, Thorson PH, Rivers J (2011) Distribution and abundance estimates for cetaceans in the waters off Guam and the Commonwealth of the Northern Mariana Islands. Pac Sci 65:321-343

Gilly WF, Markaida U, Baxter CH, Block BA and others (2006) Vertical and horizontal migrations by the jumbo squid Dosidicus gigas revealed by electronic tagging. Mar Ecol Prog Ser 324:1-17

* Giorli G, Au WWL, Ou H, Jarvis S, Morrissey R, Moretti D 
(2015) Acoustic detection of biosonar activity of deep diving odontocetes at Josephine Seamount High Seas Marine Protected Area. J Acoust Soc Am 137:2495-2501

* Giorli G, Neuheimer A, Copeland A, Au WWL (2016) Temporal and spatial variation of beaked and sperm whales foraging activity in Hawai'i, as determined with passive acoustics. J Acoust Soc Am 140:2333-2343

Goold JC (1999) Behavioural and acoustic observations of sperm whales in Scapa Flow, Orkney Islands. J Mar Biol Assoc UK 79:541-550

Goold JC, Jones SE (1995) Time and frequency domain characteristics of sperm whale clicks. J Acoust Soc Am 98:1279-1291

Gordon J (1987) The behaviour and ecology of sperm whales off Sri Lanka. PhD dissertation, Darwin College, Cambridge

Gordon J (1991) Evaluation of a method for determining the length of sperm whales Physeter catodon from their vocalizations. J Zool (Lond) 224:301-314

Griffin RB (1999) Sperm whale distributions and community ecology associated with a warm core ring off Georges Bank. Mar Mamm Sci 15:33-51

Hill MC, Ligon AD, Deakos MH, Ü AC, Milette-Winfree AJ, Oleson EM (2013) Cetacean surveys of Guam and CNMI waters: May-July, 2012: including individual photo-identification of pilot whales, spinner dolphins and bottlenose dolphins (2010-2012). Prepared for the US Pacific Fleet Environmental Readiness Office. PIFSC Data Report DR13-001. www.pifsc.noaa.gov/library/pubs/DR-13-001.pdf

Hodge LEW (2011) Monitoring marine mammals in Onslow Bay, North Carolina, using passive acoustics. PhD dissertation, Duke University, Durham, NC

Hodge LEW, Bell JT, Kumar A, Read AJ (2013) The influence of habitat and time of day on the occurrence of odontocete vocalizations in Onslow Bay, North Carolina. Mar Mamm Sci 29:E411-E427

Højsgaard S, Halekoh U, Yan J (2006) The R package geepack for generalized estimating equations. J Stat Softw 15:1-11

Irvine L, Palacios DM, Urbán J, Mate B (2017) Sperm whale dive behavior characteristics derived from intermediateduration archival tag data. Ecol Evol 7:7822-7837

Ivashchenko YV, Brownell RL Jr, Clapham PJ (2014) Distribution of Soviet catches of sperm whales Physeter macrocephalus in the North Pacific. Mar Ecol Prog Ser 25:249-263

Jaquet N (1996) How spatial and temporal scales influence understanding of sperm whale distribution: a review. Mammal Rev 26:51-65

Jaquet N, Dawson S, Douglas L (2001) Vocal behavior of male sperm whales: Why do they click? J Acoust Soc Am 109:2254-2259

Jaquet N, Gendron D, Coakes A (2003) Sperm whales in the Gulf of California: residency, movements, behavior, and the possible influence of variation in food supply. Mar Mamm Sci 19:545-562

Jochens A, Biggs D, Benoit-Bird K, Engelhaupt D and others (2008) Sperm whale seismic study in the Gulf of Mexico: synthesis report. OCS Study MMS 2008-006, Minerals Management Service, Gulf of Mexico OCS Region, US Department of the Interior, New Orleans, LA

Johnson CM, Beckley LE, Kobryn H, Johnson GE, Kerr I, Payne R (2016) Crowdsourcing modern and historical data identifies sperm whale (Physeter macrocephalus) habitat offshore of south-western Australia. Front Mar Sci 3:167
Kasuya T, Miyashita T (1988) Distribution of sperm whale stocks in the North Pacific. Sci Rep Whales Res Inst Tokyo 39:31-75

* Laran S, Drouot-Dulau V (2007) Seasonal variation of striped dolphins, fin- and sperm whales' abundance in the Ligurian Sea (Mediterranean Sea). J Mar Biol Assoc UK 87: 345-352

* Linnenschmidt M, Teilmann J, Akamatsu T, Dietz R, Miller LA (2013) Biosonar, dive, and foraging activity of satellite tracked harbor porpoises (Phocoena phocoena). Mar Mamm Sci 29:E77-E97

* Madsen P, Wahlberg M, Møhl B (2002) Male sperm whale (Physeter macrocephalus) acoustics in a high-latitude habitat: implications for echolocation and communication. Behav Ecol Sociobiol 53:31-41

Matsushita T (1955) Daily rhythmic activity of the sperm whales in the Antarctic Ocean. Bull Jpn Soc Sci Fish 20: 770-773

McClain CR, Hardy SM (2010) The dynamics of biogeographic ranges in the deep sea. Proc Biol Sci 277: 3533-3546

* Mellinger D, Stafford K, Fox CG (2004) Seasonal occurrence of sperm whale (Physeter macrocephalus) sounds in the Gulf of Alaska, 1999-2001. Mar Mamm Sci 20:48-62

Merkens KPB (2013) Deep-diving cetaceans in the Gulf of Mexico: acoustic ecology and response to natural and anthropogenic forces including the Deepwater Horizon oil spill. PhD dissertation, University of California, San Diego, CA

*Mizroch SA, Rice DW (2013) Ocean nomads: distribution and movements of sperm whales in the North Pacific shown by whaling data and Discovery marks. Mar Mamm Sci 29:E136-E165

* Møhl B, Wahlberg M, Madsen PT, Miller LA, Surlykke A (2000) Sperm whale clicks: directionality and source level revisited. J Acoust Soc Am 107:638-648

Møhl B, Wahlberg M, Madsen PT, Heerfordt A, Lund A (2003) The monopulsed nature of sperm whale clicks. J Acoust Soc Am 114:1143-1154

* Moore JE, Barlow JP (2014) Improved abundance and trend estimates for sperm whales in the eastern North Pacific from Bayesian hierarchical modeling. Endang Species Res 25:141-150

* Notarbartolo di Sciara G, Frantzis A, Bearzi G, Reeves R (2012) Physeter macrocephalus (Mediterranean subpopulation). The IUCN Red List of Threatened Species 2012: e.T16370739A16370477. http://dx.doi.org/10.2305/IUCN. UK.2012-1.RLTS.T16370739A16370477.en (accessed on 14 August 2017)

\% Ochoa J, Maske H, Sheinbaum J, Candela J (2013) Diel and lunar cycles of vertical migration extending to below $1000 \mathrm{~m}$ in the ocean and the vertical connectivity of depth-tiered populations. Limnol Oceanogr 58:1207-1214

Oshumi S (1966) Sexual segregation of the sperm whale in the North Pacific. Sci Rep Whales Res Inst Tokyo 20:1-16

*Pan W (2001) Akaike's information criterion in generalized estimating equations. Biometrics 57:120-125

* Panigada S, Zanardelli M, MacKenzie M, Donovan C, Mélin F, Hammond PS (2008) Modelling habitat preferences for fin whales and striped dolphins in the Pelagos Sanctuary (western Mediterranean Sea) with physiographic and remote sensing variables. Remote Sens Environ 112:3400-3412

* Papastavrou V, Smith SC, Whitehead H (1989) Diving behaviour of the sperm whale, Physeter macrocepha- 
Ius, off the Galapagos Islands. Can J Zool 67:839-846

Pirotta E, Matthiopoulos J, MacKenzie M, Scott-Hayward L, Rendell L (2011) Modelling sperm whale habitat preference: a novel approach combining transect and follow data. Mar Ecol Prog Ser 436:257-272

Redfern JV, Ferguson MC, Becker EA, Hyrenback KD and others (2006) Techniques for cetacean-habitat modeling. Mar Ecol Prog Ser 310:271-295

Rhines PB (2001) Mesoscale eddies. In: Steele JH, Turekian KK, Thorpe SA (eds) Encyclopedia of ocean sciences, Vol 3. Academic Press, San Diego, CA, p 1717-1730

Richardson WJ, Greene CR Jr, Malme CI, Thomson DH (1995) Marine mammals and noise. Academic Press, San Diego, CA

Roper CFE, Young RE (1975) Vertical distribution of pelagic cephalopods. Smithson Contrib Zool 209:1-51

Salvadeo CJ, Gomez-Gallardo AU, Najera-Caballero M, Urban-Ramirez J, Lluch-Belda D (2015) The effect of climate variability on gray whales (Eschrichtius robustus) within their wintering areas. PLOS ONE 10:e0134655

Schaefer KM, Fuller DW (2002) Movements, behavior, and habitat selection of bigeye tuna (Thunnus obesus) in the eastern equatorial Pacific, ascertained through archival tags. Fish Bull 100:765-788

Schaffeld T, Bräger S, Gallus A, Dähne M and others (2016) Diel and seasonal patterns in acoustic presence and foraging behaviour of free-ranging harbour porpoises. Mar Ecol Prog Ser 547:257-272

Scott-Hayward LAS, Oedekoven CS, Mackenzie ML, Walker CG, Rexstad E (2013) User guide for the MRSea package: statistical modelling of bird and cetacean distributions in offshore renewables development areas. University of St. Andrews contract for Marine Scotland; SB9 (CR/2012/05)

Seki MP, Foley DG, Bidigare RR, Polovina JJ, Leonard CL, Brainard RE (2001) Biological enhancement at cyclonic eddies tracked with GOES thermal imagery in Hawaiian waters. Geophys Res Lett 28:1583-1586

Seki M, Lumpkin R, Flament P (2002) Hawaii cyclonic eddies and blue marlin catches: the case study of the 1995 Hawaiian International Billfish Tournament. J Oceanogr 58:739-745

Simonis AE, Roch MA, Bailey B, Barlow J and others (2017) Lunar cycles affect common dolphin Delphinus delphis foraging in the Southern California Bight. Mar Ecol Prog Ser 577:221-235

Smith TD, Reeves RR, Josephson EA, Lund JN (2012) Spatial and seasonal distribution of American whaling and whales in the age of sail. PLOS ONE 7:e34905

* Soldevilla MS, Wiggins SM, Hildebrand JA (2010) Spatial and temporal patterns of Risso's dolphin echolocation in the Southern California Bight. J Acoust Soc Am 127: $124-132$

Solsona Berga A (2019) Advancement of methods for passive acoustic monitoring: a framework for the study of deep-diving cetacean populations. $\mathrm{PhD}$ dissertation, Universitat Politècnica de Catalunya, Barcelona Tech

Stanistreet JE, Nowacek DP, Bell JT, Cholewiak DM and others (2018) Spatial and seasonal patterns in acoustic detections of sperm whales Physeter macrocephalus along the continental slope in the western North Atlantic Ocean. Endang Species Res 35:1-13

Stimpert AK, DeRuiter SL, Falcone EA, Joseph J and others (2015) Sound production and associated behavior of tagged fin whales (Balaenoptera physalus) in the
Southern California Bight. Anim Biotelem 3:1-12

* Straley JM, Schorr GS, Thode AM, Calambokidis J and others (2014) Depredating sperm whales in the Gulf of Alaska: local habitat use and long distance movements across putative population boundaries. Endang Species Res 24:125-135

Taylor BL, Baird R, Barlow J, Dawson SM and others (2008) Physeter macrocephalus. The IUCN Red List of Threatened Species 2008: e.T41755A10554884. http://dx.doi. org/10.2305/IUCN.UK.2008.RLTS.T41755A10554884.en (accessed on 27 January 2017)

* Thode A, Mellinger DK, Stienessen S, Martinez A, Mulling K (2002) Depth-dependent acoustic features of diving sperm whales (Physeter macrocephalus) in the Gulf of Mexico. J Acoust Soc Am 112:308-321

Todd VLG, Pearse WD, Tregenza NC, Lepper PA, Todd IB (2009) Diel echolocation activity of harbour porpoises (Phocoena phocoena) around North Sea offshore gas installations. ICES J Mar Sci 66:734-745

Vaillancourt RD, Marraa J, Seki MP, Parsons ML, Bidigared RR (2003) Impact of a cyclonic eddy on phytoplankton community structure and photosynthetic competency in the subtropical North Pacific Ocean. Deep Sea Res I 50: 829-847

Walker C, Mackenzie M, Donovan C, O'Sullivan M (2011) SALSA - a spatially adaptive local smoothing algorithm. J Stat Comput Simul 81:179-191

*Watanabe H, Kubodera T, Moku M, Kawaguchi K (2006) Diel vertical migration of squid in the warm core ring and cold water masses in the transition region of the western North Pacific. Mar Ecol Prog Ser 315:187-197

Watkins WA, Schevill WE (1977) Sperm whale codas. J Acoust Soc Am 62:1485-1490

Watkins WA, Daher MA, DiMazio NA, Samuels A and others (1999) Sperm whale surface activity from tracking by radio and satellite tags. Mar Mamm Sci 15:1158-1180

W Watkins WA, Daher MA, DiMazio NA, Samuels A and others (2002) Sperm whale dives tracked by radio tag telemetry. Mar Mamm Sci 18:55-68

*Watwood SL, Miller PJO, Johnson MP, Madsen PT, Tyack PL (2006) Deep-diving foraging behaviour of sperm whales (Physeter macrocephalus). J Anim Ecol 75:814-825

Weilgart L, Whitehead H (1988) Distinctive vocalizations from mature male sperm whales (Physeter macrocephalus). Can J Zool 66:1931-1937

Whitehead H (2003) Sperm whales: social evolution in the ocean. University of Chicago Press, Chicago, IL

Whitehead H, Weilgart L (1990) Click rates from sperm whales. J Acoust Soc Am 87:1798-1860

Whitehead H, Weilgart L (1991) Patterns of visually observable behaviour and vocalizations in groups of female sperm whales. Behaviour 118:275-296

Wiggins SM, Hildebrand JA (2007) High-frequency acoustic recording package (HARP) for broad-band, long-term marine mammal monitoring. In: 2007 Symp Underw Technol Workshop Sci Use Submar Cables Relat Technol, Tokyo, 17-20 April 2007. IEEE, Tokyo, p 551-557

*Wong SNP, Whitehead H (2014) Seasonal occurrence of sperm whales (Physeter macrocephalus) around Kelvin Seamount in the Sargasso Sea in relation to oceanographic processes. Deep Sea Res I 91:10-16

Worthington LV, Schevill WE (1957) Underwater sounds heard from sperm whales. Nature 180:291

Zimmer W (2011) Passive acoustic monitoring of cetaceans. Cambridge University Press, Cambridge 